\title{
A PILOT STUDY OF DIETARY INTAKE IN CHILDREN
}

\author{
Mariana Dimova-Gabrovska ${ }^{1}$, Desislava Dimitrova ${ }^{2}$, Mariela Deliverska $^{3}$ \\ 1) Department of Prosthetic Dentistry, Faculty of Dental Medicine, Medical \\ University - Sofia \\ 2) Department of Pediatric Dentistry, Faculty of Dental Medicine, Medical \\ University - Varna \\ 3) Department of Ethics and Law, Faculty of Public Health, Medical University - \\ Sofia, Bulgaria.
}

\section{SUMMARY}

Adequate and balanced import of essential nutrients is of particular importance for the developing child's organism.

The purpose of the present study was to examine the intake of main macronutrients (proteins, carbohydrates, fats) from the daily diets of children aged $3-15$ years.

Material and methods: Subjects of the study were 45 children at the average age of $7 \pm 2.73$ years. Based on children and parents' data, 24-hour dietary registers were obtained for all studied children. The data on received food and fluids from the registers were analyzed, and the daily energy intake values (E\%) of proteins, carbohydrates and fats were derived.

Results: For all studied children, mean values of protein intake of $15.8 \pm 3.5 \mathrm{E} \%$, fat intake of $38.1 \pm 7.5 \mathrm{E} \%$ and carbohydrate intake of $49.5 \pm 7.31 \mathrm{E} \%$ were found.

Conclusion: The study results show that protein and carbohydrate intake values are consistent with the physiological norms for the age, while the fat intake values are above the recommended in our young patients. ergy intake

Key words: nutrition, childhood, macronutrients, en-

\section{INTRODUCTION}

Nutrition is a vital life process for the human body. The intake, disintegration and utilization of food provide the necessary energy and substances for building up and restoring the cells and tissues and realizing and regulating the vital functions [1]. Adequate nutrition is a key factor for the normal growth and development in childhood. This age period is characterized by increased nutritional and energy needs due to the high intensity of metabolic processes and the continuous new tissue formation [3].

The relationship between nutrition and oral health is scientifically proven $[4,5,6,7,8]$. The intake of nutrients has its effects on the growth and development of orofacial structures and oral mucosa and can be a major factor for the occurrence of dental diseases, such as caries, enamel defects, erosions and periodontal diseases. In addition, impaired function of oral structures and tooth loss cause pain and discom- fort while chewing various foods, reduced masticatory ability and inadequate nutrition [9].

Food has an impact on dental structures by two mechanisms [8]. After being resorbed, nutrients exert an endogenous effect on teeth prior to their eruption, thus affecting dental germination, organic matrix formation and mineralization processes. As a result of unbalanced dietary intake, enamel and dentin hypoplasias, fluorosis, reduction of tooth number, changes in tooth shape and odonoblast differentiation, pulp alterations, etc., may occur [16]. According to Alvarez et al. [10] and Psoter et al. [11], chronic malnutrition in early childhood may lead to delayed tooth eruption and exfoliation, and an increased risk of developing caries.

The pre-resorptive action of food takes place after tooth eruption and is associated with the creation of cariesogenic or caries-protective oral environment [8]. Exogenous effects of food on dental structures may cause dental diseases and dental erosions.

It is known [12] that dental disorders, partial or complete tooth loss affect masticatory efficiency, which is the main reason for limiting the intake of certain foods, the incomplete initial disintegration of nutrients, development of digestive system diseases, etc. According to Rusinova and Yordanova [13], the compromised masticatory function may lead to malnutrition or obesity in childhood. Joshipura et al. [14] have found that the reduced number of teeth is a major factor for inadequate nutrition.

The aim of this pilot study was to study the intake of main macronutrients (proteins, carbohydrates, fats) from the daily diets of children aged 3 - 15 years.

\section{MATERIALS AND METHODS}

Subjects of the study were 45 children ( 25 boys and 20 girls) at the average age of $7 \pm 2.73$ years, who were admitted at Dental Clinic "Edinstvo", for orthodontic counseling (46.7\%), treatment of carious defects $(15.6 \%)$ and regular prophylactic examination $(37.7 \%)$. Based on children and parents' data, 24-hour dietary registers were obtained, comprising the consumed food and drinks separated by hours in 3 main and 2 intermediate meals. For measuring 
the dietary intake, cooking units - teaspoon, tablespoon, tea cup, water cup, bowl, dish (portion) - were used. The obtained data on food and drink intakes were analyzed with a program for processing the dietary intake of the Bulgarian population, proposed by the National Center of Public Health and Analyzes. Values of the daily protein (energy percent, $\mathrm{E} \%)$, carbohydrate $(\mathrm{E} \%)$ and fat $(\mathrm{E} \%)$ intakes were derived.

The statistical analysis was conducted with a set of applied programs for epidemiological and clinical study data analysis - the SPSS for Windows version 22.0.0 - and included frequency analysis and cross-tabulation of qualitative variables; detection of statistically significant correlations (chi-square; Fisher's exact (two-tail) test; Student's t-test).

\section{RESULTS}

Protein intake ( $\%$ \%): In $88.8 \%$ of the study subjects, protein consumption was within the recommended range. The remaining $11.2 \%$ of the children had protein intake that exceeded the physiological norms of nutrition for the Bulgarian population (10 - 20\%) [3] (Figure 1).

Fig. 1. Protein intake in the study group

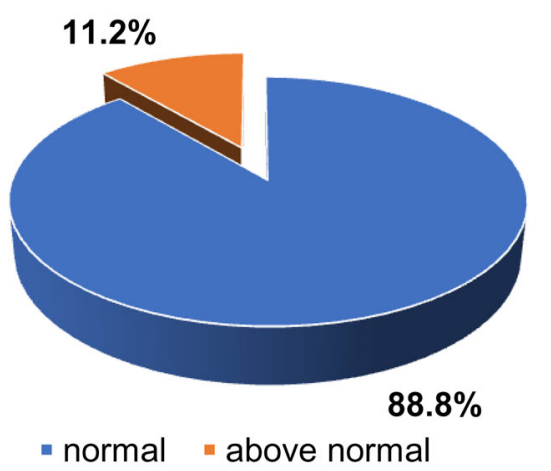

The mean daily protein intake value of $15.8 \pm 3.5 \mathrm{E} \%$ was within the recommended range.

Fat intake $(\AA \%)$ : The obtained data show that the values of fat intake were high in $46.6 \%$ of the studied children, normal in $42.2 \%$, and in only $11.2 \%$ below the recommended range for the age (25-35 E\%) [3] (Figure 2).

Fig. 2. Fat intake in the study group

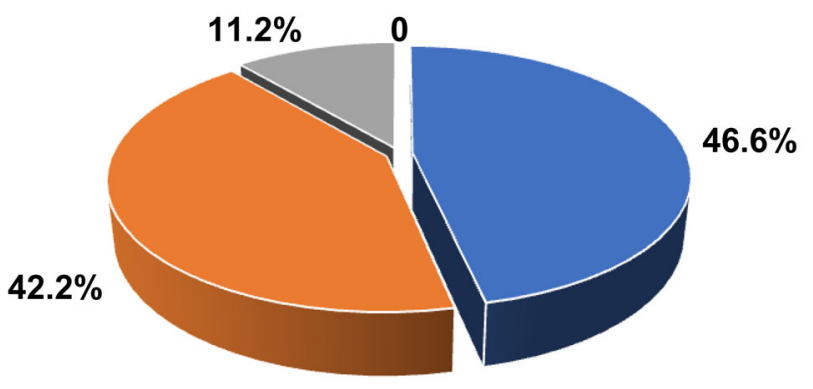

" above normal " normal " below normal
For all children, the mean daily fat intake value of $38.1 \pm 7.5 \mathrm{E} \%$ was registered. In the comparative analysis with the physiological norms, an increased fat intake of $3.1 \mathrm{E} \%$ on the average was found. The difference was statistically significant $(\mathrm{P}=0.031)$.

There was no statistical correlation between the incidence of carious lesions and the high fat intake $(\mathrm{P}=0.068)$.

Carbohydrate intake ( $\AA \%)$ : While evaluating the children's carbohydrate intake and comparing the obtained values with the physiological norms $(45-60 \mathrm{E} \%)$ [3], we found that $73.3 \%$ of the studied children had normal intake corresponding to the energy needs of the body. In $26.7 \%$ of the children, the import of carbohydrates was lower than required. In none of the studied cases, the carbohydrate intake was found to be above normal. For all children, the mean daily carbohydrate intake value of $49.5 \pm 7.31 \%$ was found (Figure 3).

Fig. 3. Carbohydrate intake in the study group

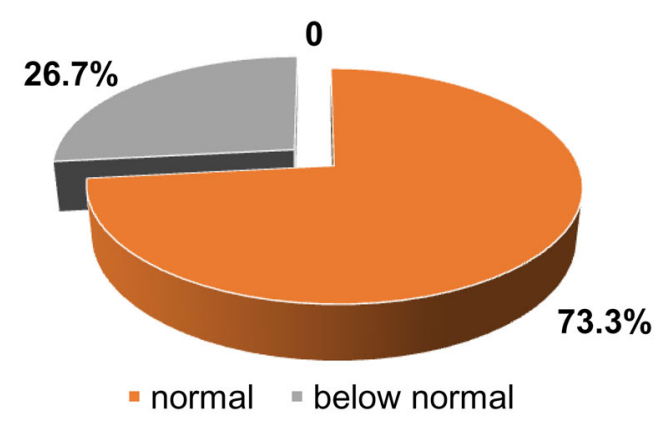

DISCUSSION

The results obtained for the protein intake are close to the daily dietary intakes of 7-10-year old children in European countries, such as England, Italy, Spain, France and the Czech Republic, reported in some scientific papers $[15,16]$. Protein consumption varied between $11-16 \%$ for the boys and 11-17.8\% for the girls.

Unlike protein intake, fat consumption is increasing globally. Increased consumption of foods, rich in hidden fats, is also observed in children [17]. The data from this study show increased intakes of fatty substances by the children aged $3-10$ years $(49.5 \pm 7.31 \mathrm{E} \%)$. This is probably due to increased consumption of fried potatoes, chips and fat-rich foods that are cited as favorites by most of the children. The reverse proportional dependence between excessive fat intake and reduced physical activity is indicated as the basic prerequisite for increased body weight and obesity worldwide [18].

The values of carbohydrate intake support the results of the foreign and Bulgarian studies so far $[2,15,20]$. The energy import from carbohydrates was between $40.3 \%$ $61.6 \%$ for the boys and $39-60 \%$ for the girls. This means that the total energy produced by the different types of carbohydrates (low and high molecular weight) meets the needs of the body for this age. 


\section{CONCLUSION}

The consumption of carbohydrates and proteins in the studied children is consistent with the physiological norms. From the carbohydrate group, however, low-molecular sugars (mono-, disaccharides, i.e. confectionery) were preferred for consuming by the children in our study, which is a major risk factor for the development of caries. According to the physiological requirements, about $2 / 3$ of the total energy, obtained from the carbohydrate intake, should be provided by high molecular fibers and only $1 / 3$ by simple sugars [3]. These data draw attention to the need for a wider, more modern study of carbohydrate intake among children in different age groups and a well-founded interpretation of the results in relation to the nutritional impact on both children's general health and dental status.

This pilot study shows increased fat intake in the studied children due to the high consumption of foods rich in hidden fatty substances.

These data are disturbing because it is known that excessive intake of substances and energy has an adverse effect on the child's organism. Excessive nutrition may lead to obesity, increased number of fat cells, increased risk of diabetes, atherosclerosis, etc. [19].

\section{Inferences:}

The significance of the presented issues emphasizes on the need to introduce and follow prophylactic programs for adequate and balanced nutrition in the childcare facilities, which to be accompanied by full-value resources for parents' information and motivation with regard to important aspects of nutrition in each age group.

Monitoring of the child's dietary pattern and nutritional habits should be carried out by both the GP and the dentist. Nutrition studies should be part of the regular prophylactic dental examinations, thus emphasizing the importance of a functionally fit masticatory system as a part of the digestive system and providing prerequisites for the prevention of malnutrition due to impaired dental structures.

\section{REFERENCES:}

1. Russell MK. Functional assessment of nutrition status. Nutr Clin Pract. 2015 Apr;30(2):211-8. [PubMed] [Crossref]

2. Hebestreit A, Börnhorst C, Pala V, Barba G, Eiben G, Veidebaum T, et al. Dietary energy density in young children across Europe. Int $J$ Obes (Lond). 2014 Sep;38 Suppl 2:S124-34. [PubMed] [Crossref]

3. Ordinance No. 1 from 30. 11. 2017 for physiological norms for nutrition of the population of Bulgaria. Ministry of Health. Bulgaria. [in Bulgarian]

4. Konstantinova D, Dimova M. Terms for characterization of the chewing function. Social medicine. 2016; 3(4):37-39. [in Bulgarian]

5. Konstantinova D, Pancheva R, Dimova M. Trends in the state of dental status in boys and girls of high school age in Varna. Practical Pediatrics. 2013; 7: 16-18. [in Bulgarian]

6. Rashkova M, Mitova N, Lozanov B, Russeva S, Mateva A, Zhegova G. Metabolic analysis of saliva - products of the protein metabolism in saliva and oral pathology in children. Problems of dental medicine. 2014; 40 (2): 13-21. [in Bulgarian]

7. Andreeva R, Arnautska H, Georgieva M, Dimitrov E, DimovaGabrovska M. Importance of the carious activity of the parents in connection with the premature tooth loss of their children. Medinform. 2016 June;3(1):404-408. [Crossref]

8. Moynihan PJ. The role of diet and nutrition in the etiology and prevention of oral diseases. Bull World Health Organ. 2005 Sep;83(9):694699. [Internet]

9. Ngoenwiwatkul Y. LeelaAdisorn N. Effects of dental caries on nutritional status among first-grade primary school children. Asia Pac Public Health. 2009; 21(2):177-183. [Crossref]

10. Alvarez JO, Lewis CA, Saman C, Caceda J, Montalvo J, Figueroa ML, et al. Chronic malnutrition, dental caries, and tooth exfoliation in Peruvian children aged 3-9 years. Am J Clin Nutr. 1988 Aug;48(2):368-72. [PubMed] [ $\underline{\text { Crossref] }}$

11. Psoter W, Gebrian B, Prophete S, Reid B, Katz R. Effect of early childhood malnutrition on tooth eruption in Haitian adolescents. Community Dent Oral Epidemiol. 2008

\section{Apr;36(2):179-189. [Crossref]}

12. Mojon P, Budtz-Jorgensen E, Rapin CH. Relationship between oral health and nutrition in very old people. Age Ageing. 1999 Sep;28(5):4638. [PubMed]

13. Russinova M, Iordanova A. Nutrition in childhood. Contemporary aspects. MedInfo 2016; 8 [in Bulgarian]

14. Joshipura KJ, Willett WC, Douglass CW. The impact of edentulousness on food and nutrient intake. J Am Dent Assoc. 1996 Apr;127(4): 459-67. [PubMed] [Crossref]

15. Lambert J, Agostoni C, Elmadfa I, Hulshof K, Krause E, Livingstone B, et al. Dietary intake and nutritional status of children and adolescents in Europe. Br J Nutr. 2004 Oct;92 Supp1 2:S147-211. [PubMed] [Crossref]

16. Cruz JA. Dietary habits and nutritional status in adolescents over Europe - Southern Europe. Eur J Clin Nutr. 2000 Mar;54 Suppl 1:S29-35. [PubMed]

17. Ervin RB, Ogden CL. Trends in intake of energy and macronutrients in children and adolescents from 1999-2000 through 2009-2010. 
NCHS Data Brief. 2013 Feb;(113):18. [PubMed]

18. Güngör NK. Overweight and obesity in children and adolescents. J Clin Res Pediatr Endocrinol. 2014 Sep; 6(3):129-43. [PubMed] [Crossref]
19. Ministry of Health and National center of Public Health - Bulgaria. National study of the risk factors for health 2014 y. National Program for prevention of the chronic non-infectious diseases 2014-2020 y. [in Bulgarian]

Please cite this article as: Dimova-Gabrovska M, Dimitrova D, Deliverska M. A pilot study of dietary intake in children. $J$ of IMAB. 2018 Oct-Dec;24(4):2254-2257. DOI: https://doi.org/10.5272/jimab.2018244.2254

Received: 08/08/2018; Published online: 29/11/2018

\section{Corresponding author:}

Assoc. Prof. Dr Mariana Dimova-Gabrovska, PhD, DSc.

Department of Prosthetic Dentistry, Faculty of Dental Medicine, Medical University, Sofia,

1, St. G. Sofiiski Blvd., 1431 Sofia, Bulgaria

E-mail: marianadimova@abv.bg 